\title{
Commentary: Prehabilitation for increasing ventilatory efficiency before lung resection: Amazing concept, but we're not there yet!
}

\author{
Walid Ben Ali, MD, FRCSC, ${ }^{\mathrm{a}}$ Moishe Liberman, MD, PhD, FRSCS, ${ }^{\mathrm{b}}$ and \\ Louis P. Perrault, MD, PhD, FRCSC ${ }^{\mathrm{c}}$
}

\footnotetext{
From the a Division of Cardiac Surgery, Department of Cardiac Surgery, Montreal Heart Institute, Université de Montréal, Montreal, Quebec, Canada; ${ }^{\mathrm{b}} \mathrm{CHUM}$ Endoscopic Tracheobronchial and Oesophageal Center, Centre Hospitalier de l'Université de Montréal, Division of Thoracic Surgery, Université de Montréal, Montreal, Quebec, Canada; and ${ }^{\mathrm{c} D}$ Division of Cardiac Surgery, Department of Cardiac Surgery, Montreal Heart Institute, Université de Montréal, Montreal, Quebec, Canada.

Disclosures: Authors have nothing to disclose with regard to commercial support.

Received for publication Feb 20, 2019; accepted for publication Feb 20, 2019; available ahead of print April 4, 2019.

Address for reprints: Moishe Liberman, MD, PhD, FRSCS, Centre Hospitalier de l'Université de Montréal Centre de Recherche du CHUM, Room R04.402-1 900 Rue Saint-Denis, Montreal, Quebec, Canada H2X 0A9 (E-mail: moishe.liberman@umontreal.ca).

J Thorac Cardiovasc Surg 2019;157:2513-4

$0022-5223 / \$ 36.00$

Copyright (c) 2019 by The American Association for Thoracic Surgery

https://doi.org/10.1016/j.jtcvs.2019.02.094
}

Gravier and colleagues ${ }^{1}$ report on a cohort of 50 patients who underwent prehabilitation by high-intensity interval training (HIIT) before lung resection for non-small cell lung cancer. The article addresses an important issue in lung cancer surgery; however, because of its retrospective nature, it is difficult to determine whether successful prehabilitation ( $>15$ sessions) had a significant clinical impact. The investigators found no favorable effect of HIIT on the linear regression of the ratio between the increase in minute ventilation and the expired carbon dioxide flow (VE/VCO2) slope, but there was a positive effect on maximal oxygen uptake peak. This is a more commonly used measure for planning treatment strategies along with forced expiratory volume in 1 second and diffusing capacity of the lung for carbon monoxide. Of note, in this limited cohort, the diffusing capacity of the lung for carbon monoxide was low. According to the authors, the VE/VCO2 slope was chosen as a primary end point because it has attracted interest by several teams and could be a powerful statistical marker of complications. Unfortunately, there was no significant difference in postoperative length of stay or complications between those undergoing more than 15 versus less than 15 sessions. However, those with greater than 15 sessions numerically had less respiratory complications $(58.3 \%$ vs $37 \%$ ). The small sample size of the study may have not allowed for significant differences to be obtained.

The concept of prehabilitation to increase ventilatory efficiency before lung resection for non-small cell lung cancer has merit and may be beneficial, ${ }^{2-4}$ similar to the way it has been shown to be valuable in chronic respiratory diseases and nonthoracic surgery. ${ }^{5,6}$ The future focus should be on the determination of the optimal protocols,

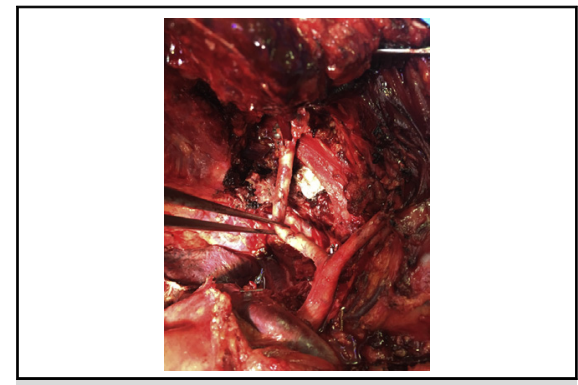

Right upper lobe Pancoast, subclavian artery, superior vena cava resection, and reconstruction.

\section{Central Message}

Prehabilitation before lung resection may be beneficial in increasing ventilatory efficiency. Optimal protocols need to be developed.

See Article page 2504 duration, and frequency of HIIT training in larger, highpowered controlled trials to improve results after lung resection surgery for lung cancer. At the Université de Montréal, we have begun enrolling in the randomized controlled trial "Preoperative Inspiratory Muscle Training Program to Prevent Pulmonary Complications After Thoracic Surgery (CT0076)" (ClinicalTrials.gov Identifier: NCT03747380: https://clinicaltrials.gov/ct2/show/NCT037 47380), looking to recruit 200 patients over 8 months to show a $50 \%$ decrease in the rate of complications at 30 days. $^{7}$ As of today, we're not there yet!

\section{References}

1. Gravier F-E, Bonnevie T, Boujibar F, Medrinal F, Prieur G, Yann C, et al. Effect of prehabilitation on ventilatory efficiency in non-small cell lung cancer patients: a cohort study. J Thorac Cardiovasc Surg. 2019;157:2504-12.

2. Tarumi S, Yokomise H, Gotoh M, Kasai Y, Matsuura N, Chang SS, et al. Pulmonary rehabilitation during induction chemoradiotherapy for lung cancer improves pulmonary function. J Thorac Cardiovasc Surg. 2015;149:569-73.

3. Bertani A, Ferrari P, Terzo D, Russo E, Burgio G, De Monte L, et al. A comprehensive protocol for physiokinesis therapy and enhanced recovery after surgery in patients undergoing video- assisted thoracoscopic surgery lobectomy. J Thorac Dis. 2018;10(Suppl 4):S499-511.

4. Zhou K, Su J, Lai Y, Li P, Li S, Che G. Short-term inpatient-based high-intensive pulmonary rehabilitation for lung cancer patients: is it feasible and effective? $J$ Thorac Dis. 2017;9:4486-93. 
5. Bailey SJ, Romer LM, Kelly J, Wilkerson DP, DiMenna FJ, Jones AM. Inspiratory muscle training enhances pulmonary $\mathrm{O}(2)$ uptake kinetics and high-intensity exercise tolerance in humans. J Appl Physiol. 2010;109: 457-68.

6. Hulzebos EH, Helders PJ, Favie NJ, de Bie RA, de la RAB, van Meeteren NL. Preoperative intensive inspiratory muscle training to prevent postoperative pulmo- nary complications in high-risk patients undergoing CABG surgery: a randomized clinical trial. JAMA. 2006;296:1851-7.

7. Liberma M, Godin A. Pre-operative inspiratory muscle training program to prevent pulmonary complications after thoracic surgery (CT0076). ClinicalTrials.gov Identifier: NCT03747380. Available at: https://clinicaltrials.gov/ct2/show/ NCT03747380. Accessed March 29, 2019. 